\title{
DIFICULDADES DE APRENDIZAGEM E A PANDEMIA: AGRAVAMENTO OU EVIDENCIAMENTO DA DIFICULDADE JÁ EXISTENTE?
}

\author{
Thamires Maia Paula Oliveira ${ }^{1}$ \\ Karollainy Gonçalves Coelho Carvalho'
}

RESUMO: A presente reflexão tem a intencionalidade de demonstrar os evidenciamentos e agravamentos causados pela pandemia nas dificuldades de aprendizagem do ensino fundamental. Sabe-se que após a inserção da tecnologia na vida cotidiana, as crianças têm se dispersado com mais facilidade, apresentado ansiedade e falta de interesse nas exposições tradicionais das atividades escolares. No entanto, a análise mostra que a pandemia apenas elevou o estágio em que esse indivíduo já se encontrava, as aulas remotas deixaram as casas e famílias mais vulneráveis e suscetíveis as observações técnicas dos professores. Constatamos então, que as crianças que já eram estimuladas e assistidas pelos pais, não apresentaram fartas dificuldades de adaptação e as mesmas tiveram o desempenho esperado para a faixa etária, enquanto as crianças que tiveram menores desempenhos e crescente dificuldades expostas, trata-se de crianças com baixa autoestima, baixa autonomia e desprovidas de apoio e assistência familiar.

Palavras-chave: Aprendizagem. Dificuldades. Pandemia.

ABSTRACT: This reflection is intended to demonstrate the evidence and aggravation caused by the pandemic in learning difficulties in elementary school. It is known that after the insertion of technology into everyday life, children have been more easily dispersed, showing anxiety and lack of interest in the traditional exhibitions of school activities. However, the analysis shows that the pandemic only raised the stage that this individual was already at, remote classes left homes and families more vulnerable and susceptible to technical observations from teachers. We then found that children who were already stimulated and cared for by their parents did not

\footnotetext{
${ }^{1}$ Graduada em Pedagogia pela UNICESUMAR-PR. Pós-graduada em Gestão de pessoas e RH, Mestranda em Educação PPGE - UFT Palmas.E-mail: thamiresmaia@hotmail.com.

${ }^{2}$ Graduada em Psicologia pela Faculdade católica Dom Orione (FACDO-TO). E-mail: karollainy84@gmail.com.
} 
have a lot of adaptation difficulties and they had the expected performance for their age group, while the children who had lower performances and increasing exposure difficulties are children with low self-esteem, low autonomy and lack of family support and assistance.

Keywords: Difficulties. Learning. Pandemic.

\section{INTRODUÇÃO}

A capacidade de aprendizado das crianças está diretamente ligada ao nível de amadurecimento emocional que ela contém em consonância com sua idade, enquanto a criança cresce e se desenvolve, sua capacidade de aprendizagem se amplia de acordo com os estímulos que ela vivência em casa, na escola e no meio em que se encontra. A maturidade emocional é um importantíssimo estímulo, onde os pais e o meio de vivência exercem a função dessa influência e prospecção de exemplos que a mesma seguirá inconscientemente, lidar com estresse e mudanças, habilidades de socialização e capacidade de aprender, já que seu campo visual prático é aguçado. Claro que somente esse fator não é dominante para que a aprendizagem da criança não sofra dificuldades, apenas é certo que o fator emocional é o maior processo de estímulo que os pais podem abastecer ao longo da vida da criança.

Com o início da pandemia causada pela COVID ı9, o mundo se deparou com um cenário ainda não vivido, todos precisaram se adaptar de alguma forma, no modo de trabalhar, na vida social e não obstante a escola se viu compelida a oferecer a extensão das suas atividades até as casas de seus alunos. Principiando do ensino EAD, as escolas de ensino fundamental foram moldando seus planejamentos escolares e suas aulas para o modo remoto, levando às as crianças a continuidade da aprendizagem de casa.

Nesse momento, mais que nunca, a família precisou amparar os filhos no ensino remoto e exercer o dever garantido por todas as crianças e adolescentes: De acordo com o art. 22ㅇ do Estatuto da Criança e do Adolescente, (Lei n.8.069, de 13 de julho de 199o): “Aos pais incumbe o dever de sustento, guarda e educação dos filhos menores, cabendo-lhes ainda, no interesse destes, a obrigação de cumprir e fazer cumprir as determinações judiciais. Parágrafo único. A mãe e o pai, ou os responsáveis, têm direitos iguais e deveres e responsabilidades compartilhados no cuidado e na educação da 
criança, devendo ser resguardado o direito de transmissão familiar de suas crenças e culturas, assegurados os direitos da criança estabelecidos nesta Lei.

O público de estudantes é bastante heterogêneo e por esse exato motivo, cada indivíduo tem suas facilidades e dificuldades diferentes um dos outros, portanto, aqueles que foram poucos estimulados e assistidos, claramente tiveram a adaptação menos favorável no processo do novo modelo de ensino.

Essa pesquisa coloca em discussão as dificuldades de aprendizagem que foram aguçadas durante a pandemia através das ministrações de aulas remotas. Essa seria a alegação correta, ou esse modelo de ensino foi apenas o gatilho para a exposição de uma disfunção já existente?

Através de entrevistas com atuantes da educação do fundamental nas aulas remotas e embasamentos científicos, desdobraremos toda a problemática analisada entre alunos, professores e famílias que viveram e vivem o enfrentamento das dificuldades de aprendizagem. No decorrer dessa análise atingiremos os caminhos propícios a serem percorridos pela família e profissionais da educação, onde encontrarão as habilidades que deverão ser desenvolvidas para que essa deficiência seja recuperada e haja progresso contínuo a esse indivíduo.

\section{DESENVOLVIMENTO COGNITIVO E EMOCIONAL DAS CRIANÇAS}

As crianças de hoje nascem em meio a muitas tecnologias, visualizam telas desde pequenas e aprendem a lidar com elas antes mesmo de aprender a andar e falar; sim, vivemos em um mundo globalizado e altamente tecnológico o que já é influência suficiente para que os pequenos tenham esse contato tão cedo.

O que ocorre é que as tecnologias são utilizadas freneticamente como ferramenta de entretenimento por grande parte do tempo, de tal maneira que a criança vive sua maior parte do dia em um mundo paralelo ao real. Os pais, utilizando de justificativas de que as crianças ficam mais calmas e que estão ocupados, com pressa, para deixarem de se aborrecer, ou se ocupar conversando, orientando, estimulando novas experiências como olhar pela janela enquanto percorre caminhos entre a casa e a escola ou entre a cidade e uma chácara, preferem entregar à criança um celular ou tablet para que tenham tranquilidade nesse percorrer de percurso. 
E o efeito dessas permissividades são a perca de momentos valiosos entre o relacionamento parental, a formação das crianças são decorrentes dos estímulos que recebe diariamente do meio que as cercam, desenvolvem-se a partir de comportamentos espelhados dos seus pais ou responsáveis.

Os estudos neurocientíficos evidenciam que a interação dos pais com seus filhos estimula o desenvolvimento cerebral, o crescimento emocional e a aprendizagem. Além disso, esses relacionamentos sociais são grandes preditores para a felicidade (SIEGEL, 2020, p. 73).

Contudo, diante a exposição de tantas tecnologias, essas crianças acostumam-se a realidades acordáveis com o que elas determinam e passam a fazer exigências com as quais está aprendendo, o jogo por exemplo, enquanto as fases estão sendo vencidas, prossegue-se sem interrupções, já quando se perde, elas buscam outro, mudam a tela sem ao menos fazer novas tentativas.

Daí o resultado do grande problema dessa geração: a incapacidade de lidar com frustrações, que se transpõe para os relacionamentos sociais. Se não dá certo com uma pessoa, as criancinhas a agridem, deixam-na de ado, buscam outra. Descartam-na como se fosse videogame (TIBA, 2002, p. 234).

Crianças incapazes de ter convívio social tornam-se despreparados emocionalmente, desobedientes, necessitados de afeição, incontroláveis, coléricos e desestruturados para uma aprendizagem eficaz. A falta de habilidade familiar tem sido crescente nos lares brasileiros, pessoas cada vez mais ocupadas e estressadas não conseguem equilibrar e organizar o tempo entre seus problemas profissionais, pessoais com momentos de lazer e incentivo aos filhos a terem momentos proveitosos juntos.

A tecnologia é global, por isso os erros cometidos às análises e diagnósticos também são, em todo o mundo neurologistas, psicopedagogos e outros profissionais da área estão diagnosticando essas crianças com déficit de atenção precocemente. Augusto Cury explica que a síndrome do pensamento acelerado é o diagnóstico correto e cada dia será mais comum entre as crianças e adolescentes pelo fato de estarmos em uma crescente evolução da tecnologia. Somos todos educados para cumprir funções mecanizadas, ensina-se a escovar os dentes, a tomar banho, 
mas não se ensina a ter saúde mental, dificilmente nos dias atuais, se ensina a uma criança que se frustrar é normal, mas sim se é ressaltada a importância de ganhar.

Não se ensina a estudar para aprender, ter pensamento crítico, mas para ter boas notas e obter a aprovação na universidade que comumente foi sonhada e escolhida pelos pais desde que a criança começou a existir. Infelizmente essa falta de habilidades somadas ao excesso da tecnologia estão adoecendo principalmente os menores, a falta de condução correta perante às dificuldades, fazem com que elas se transformem em grandes e difíceis questões de se controlar.

A vulnerabilidade da psique conhecida como SPA - síndrome do pensamento acelerado, dificulta o entendimento das informações como conhecimento, em consequência a experiência e a inteligência, levando o indivíduo a não reconhecer quando necessário expor suas próprias ideias, ter empatia e organizar seus pensamentos.

Alguns jovens só conseguem perceber algo errado em sua vida quando se tornam adultos frágeis, dependentes, ansiosos, cujos sonhos foram enterrados nos becos da história. Alguns pais só conseguem perceber a crise familiar depois que suas relações com os filos estão esfaceladas, sem respeito, afeto e amor. Alguns casais só conseguem perceber que sua relação está falida depois que vivem o inferno dos atritos. Alguns profissionais só conseguem perceber que não são produtivos, proativos, criativos depois que perderam o encanto pelo trabalho, quando estão na lama da frustração (CURY, 2014, p.29).

Novamente impelimos a responsabilidade aos familiares, $90 \%$ da influência que os pais exercem no desenvolvimento das crianças ao que se refere à personalidade é espelho do que os mesmos agem na fala, correções, e afiam aos indivíduos.

Qual o caminho para melhorar o relacionamento entre as famílias? Como conectar pais e filhos para encorajá-los a serem cidadãos mais felizes, autônomos, estudiosos, criativos, éticos, bem-sucedidos? É mais significativo e importante a qualidade do tempo em que se dedica aos filhos do que a quantidade de tempo que é disposto para estar em companhia deles.

A escola deve ser a extensão familiar, trabalhar as emoções junto aos conteúdos, ensinar os alunos a serem mais críticos e reflexivos e não repetidores de informações, aprender a aprender e ressignificar os métodos utilizados para que todos tenham sucesso em suas jornadas. Ser autônomo de sua própria história, evoluir e auxiliar os colegas ao entorno ao mesmo, praticar 
a empatia e socializar os conhecimentos para que os pensamentos se complementem, praticar a abertura de novas janelas no cérebro, transformando essa grande caixa em uma potência poderosa e altruísta.

\section{PROCESSO METODOLÓGICO, APRESENTAÇÃO E DISCUSSÃO DOS DADOS}

Em pesquisa com profissionais da educação que ministraram aulas remotas durante a pandemia, destacamos pontos importantes que nos levam ao entendimento de que a mudança do meio da aprendizagem não causou, mas apenas evidenciou a dificuldade já existente na criança.

Como os alunos já haviam frequentado à escola por dois meses presencialmente, conseguimos as informações que demonstram nitidamente que as crianças que não tiveram bom desempenho nas aulas remotas, já haviam apresentado inabilidade nas aulas presenciais, tanto quanto, o apoio familiar. Crianças que chegavam pontualmente à escola, continuaram acessando pontualmente as aulas online, crianças participativas e interessadas em aprender, continuaram demostrando entusiasmo em participar e interagir nas aulas online, assim como as mesmas crianças que entregavam as atividades pontualmente, exerciam do uso da criatividade e interação, prosseguiram reproduzindo as mesmas ações nas aulas remotas.

Em contraposta, os alunos que pouco se integravam em sala de aula, não se envolviam aos assuntos explorados, não apresentavam suas atividades regularmente, chegavam atrasados, esqueciam materiais, não continha autonomia de responder por sua vida acadêmica, demonstraram menos interesse e mais dificuldades nas aulas remotas. Seus responsáveis sentiram intensamente as adversidades na adaptação das aulas, a falta de habilidade em determinar regras, dispor de tempo para acompanhar os ofícios educacionais dos filhos, fizeram com que os mesmos tomassem atitudes irracionais como por exemplo, desobrigar o filho a assistir as aulas, culpar a escola como único portador da responsabilidade de educar, sentir-se no direito de descumprir prazos estabelecidos pela escola.

Atitudes essas, que apenas alimentam a incapacidade dos filhos a lidarem com os obstáculos da vida; não aprender a lidar com as frustrações e contraposições em que o mundo 
nos coloca, é criar um indivíduo incapaz de resolver seus próprios problemas, provavelmente um futuro portador de algum tipo de distúrbio emocional e comportamental.

Observando os relatórios que as profissionais do quarto ano do ensino fundamental I, fornecem bimestralmente à coordenação da instituição, analisamos cinco perguntas que personifica nossa reflexão utilizada para a abordagem das dificuldades de aprendizagem anteriores e posteriores à pandemia. Os resultados foram inseridos em um gráfico para que a visualização fosse facilitada.

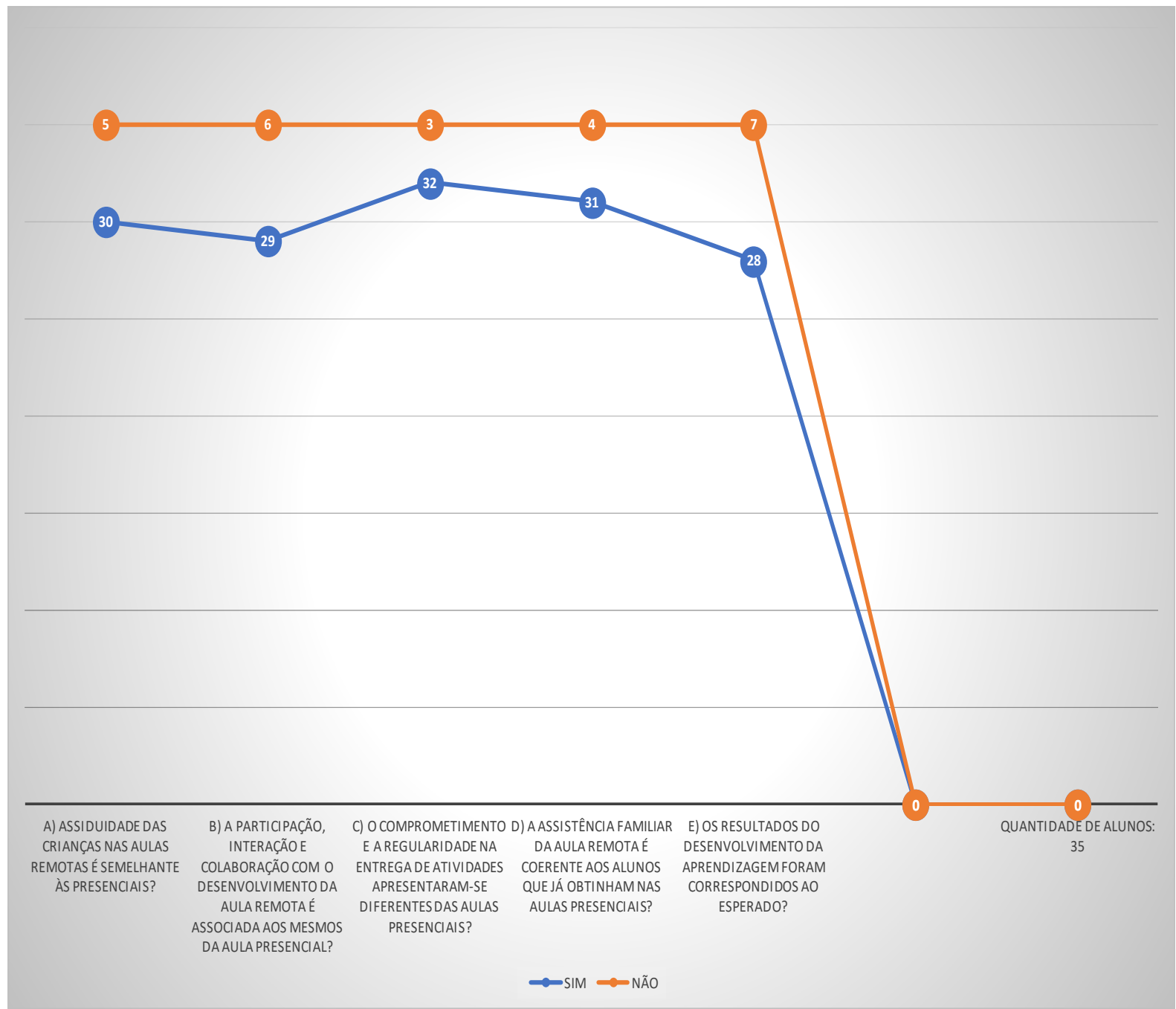




\section{CONSIDERAÇÕES FINAIS}

Com base no que foi apresentado, as dificuldades de aprendizagem têm sua origem biológica familiar, as tecnologias aceleraram e expuseram às crianças a mais fatores que as depreciassem no processo das aprendizagens. Contudo, não há como direcionar a culpabilidade somente nas tecnologias, é um conjunto de fatores e ações dentre os estímulos, assistência e exposição excessiva às tecnologias.

O estudo nos mostra o quanto temos uma nova sociedade altamente vulnerável aos efeitos da globalização, os males já causados podem ser reversíveis, mas o tratamento deve ser eficaz e urgente entre os familiares e escola, assumindo responsavelmente a função de condutores desses indivíduos. Como vimos diante os conteúdos aprestados, a prevenção ainda é o melhor remédio, contudo, é necessário o enfrentamento das famílias às causas. O entendimento das ações, exemplos e funções de cada ambiente social que essa criança convive e dela se constrói, será o esteio para garantir a mínima qualidade de vida que esse indivíduo necessita para ser um ser integral.

\section{REFERÊNCIAS}

ECA - Estatuto da criança e do adolescente, promulgada em 13/07/199o, publicada no DOU de 16/o7/1990 e retificada no DOU de 27/o9/1990.

CHAPMAN, Gary; CAMPBELL, Ross. As cinco linguagens do amor das crianças. $2^{\underline{a}}$ ed. vol.I. São Paulo: Mundo cristão, 2017.

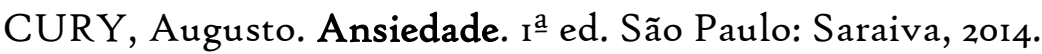

SIGEL, Daniel; PAYNE, Tina. O cérebro da criança. Ia‥ ed. São Paulo: Editora nVersos, 2015. TIBA, Içami. Quem ama educa! I4ª . ed. vol. ı. São Paulo: Editora Gente, 2002. 